Montalvo et al., Afr., J. Infect. Dis. (2018) 12 (2): 47-54

https://doi.org/10.21010/ajid.v12i2.8

\title{
BIOIMPEDANCE MARKERS AND TUBERCULOSIS OUTCOME AMONG HIV-INFECTED PATIENTS
}

\begin{abstract}
Raúl Montalvo $^{1,2^{*}}$, Antonio Bernabe-Ortiz ${ }^{3,4}$, Daniela E. Kirwan ${ }^{5}$, Robert H. Gilman ${ }^{6}$
${ }^{1}$ Universidad Continental, Huancayo Perú. ${ }^{2}$ Servicio de Enfermedades Infecciosas y Tropicales, Hospital Daniel Alcides Carrión, Huancayo, Perú. ${ }^{3}$ CRONICAS Center of Excellence in Chronic Diseases, Universidad Peruana Cayetano Heredia, Lima, Peru. ${ }^{4}$ Escuela de Medicina, Facultad de Ciencias de la Salud, Universidad Peruana de Ciencias Aplicadas, Lima, Peru. ${ }^{5}$ Infectious Diseases and Immunity and Wellcome Trust Imperial College Centre for Global Health Research, Imperial College London, United Kingdom. ${ }^{6}$ Program in Global Disease Epidemiology and Control, Department of International Health, Bloomberg School of Public Health, Johns Hopkins University, Baltimore, USA
\end{abstract}

*Corresponding Author E-mail: otivo3@ hotmail.com

\begin{tabular}{|l|}
\hline \multicolumn{1}{|c|}{ Article History } \\
Received: Sept. 02, 2017 \\
Revised Received: Feb. 09, 2018 \\
Accepted: Feb 12, 2018 \\
Published Online: June. 18, 2018 \\
\hline
\end{tabular}

Abstract

Background: The changes in body composition markers (weight, fat mass, lean mass, and BMI) over time can be associated with TB treatment outcome among HIV-infected patients. The aim of this study was to investigate whether changes in fat mass and lean mass were associated with the treatment response among patients with HIV infection and pulmonary tuberculosis.

Materials and Methods: This was a prospective cohort study. Data from HIV-infected patients commencing TB therapy were analyzed. This included body weight measurement using bioimpedance equipment at baseline, one month, and two months after starting TB treatment.

Results: The study was conducted in 125 patients, 17 patients (13.6\%) died during treatment, of which 5 died during the first month of treatment, 4 during the second month and 8 after the second month. The group of patients with good response, increased their weight by $1.3 \mathrm{~kg}(\mathrm{p}<0.001)$ at the end of the first month of TB treatment and $2.6 \mathrm{~kg}$ in the second month ( $\mathrm{p}<0.001)$, and body fat increase was $1.2 \mathrm{Kg}(\mathrm{p}<0.001)$ and $2.3 \mathrm{~kg}(\mathrm{p}<0.001)$, the first and second month respectively. The group of patients who died had lost $2.1 \mathrm{~kg}$ fat mass after the first month $(\mathrm{p}<0.001)$ and $3.7 \mathrm{~kg}$ in the second month $(\mathrm{p}<0.001)$.

Conclusions: Our results show that the weight change during TB treatment (increased fat mass) helps us predict therapeutic response. Weight loss during the first month of starting therapy should be evaluated thoroughly to identify the probable cause of treatment failure.

Keywords: HIV / AIDS; bio impedance; tuberculosis; body weight gain.

\section{Introduction}

Despite the existence of adequate treatment, tuberculosis (TB) is one of the leading causes of respiratory morbidity and mortality among HIV-infected people worldwide, accounting for $44 \%$ of all deaths related to AIDS (Ackah et al., 1995). In 2012 around 13\% of the 8.7 million TB cases were positive for HIV (UNAIDS 2013), in addition, HIV infection increases the risk of acquiring $M$. tuberculosis primary infection between 2.2 and 5.5 times (Crampin et al., 2010; Sonnenberg et al., 2001), and the risk of TB reactivation up to 20 times. As a result, every year, around 5-15\% of HIV-infected individuals experience $M$. tuberculosis reactivation (Pawlowski et al., 2012).

Many countries, including Peru, the patients' weight is checked every month during TB treatment to assess therapy response (Bernabe et al., 2011; Ott et al., 1993). Weight loss is an important sign of active disease in TB, and can be considered a marker of disease severity as different cytokines and inflammatory components are responsible for hyporexia and hypercatabolism (Schwenk et al., 2000; Zhang et al., 1997). Moreover, weight loss during the intensive phase of treatment is considered a risk factor for therapy failure (Schon et al., 2011).

Several methods of measuring body weight have been described. Bioelectrical impedance analysis (BIA) is one technique that also determines body composition. BIA measures the impedance of water, facilitating evaluation of total body water, and hencing body fat and muscle mass. It has been validated in many diseases (Dioum et al., 2005; Zhou et al., 2011); however, there is scarce literature assessing the use of this technique in HIV and TB coinfected 
populations (Mupere et al., 2010; Schwenk et al., 1999). Moreover, to the best of our knowledge, the use of bioelectrical impendace has not been evaluated to predict tuberculosis treatment outcome among HIV and TB coinfected individuals.

Therefore, we aimed to assess whether changes in BIA markers, including weight, total body water, fat mass, lean mass (non-fat mass), and BMI, over time were associated with treatment outcome (i.e. deaths during treatment) among patients with HIV infection and pulmonary tuberculosis.

\section{Materials and Methods Study design and setting}

A longitudinal prospective cohort study was conducted by enrolling consecutive HIV-infected patients with confirmed TB diagnosis (MINSA 2013). Participants were recruited from two tertiary-level hospitals in Lima, Peru (Hospital Nacional Dos de Mayo and Hospital Nacional Daniel Alcides Carrion) from January 2012 to October 2014.

\section{Study population and selection criteria}

HIV-infected patients, aged $\geq 15$ years, with or without highly-active anti-retroviral therapy (HAART) who had been newly diagnosed with pulmonary tuberculosis (aputum smear positive for acid-fast bacilli (AFB) and/or culture-positive) were asked to participate in the study. Patients who had been taking TB treatment for two weeks or more were excluded from the study.

The outcome of interest was body composition assessed by five different anthropometric markers. The TBF300A body composition analyzer (Multi-Frequency Tanita Corporation, Tokyo, Japan), a portable device was used to measure weight $(\mathrm{Kg})$, fat mass $(\mathrm{Kg})$, fat-free mass (or lean mass, $\mathrm{Kg}$ ), total body water $(\mathrm{Kg})$, and $\mathrm{BMI}\left(\mathrm{Kg} / \mathrm{m}^{2}\right)$. These markers were measured with a precison of $0.1 \mathrm{Kg}$ according to manufacturer's guidelines (TANITA 2012). As the main aim of the study was to predict overall treatment outcome, all of these proposed markers were evaluated at the start of treatment (baseline) and monthly, measuring only during the intensive phase of TB treatment (i.e. during the first two months of therapy).

The main exposure was overall mortality, defined as those patients who died during TB treatment considering the total time of therapy (i.e. six months).

Other variables of interest included in the analysis were sex, age (in years), receiving HAART during TB treatment (yes/no), self-report of previous TB prophylaxis with isoniazid (yes/no) and presence of other co-morbidities including other infectious diseases during treatment. In addition, $\mathrm{CD}_{4}$ count $\left(<200\right.$ and $\left.\geq 200 \mathrm{cells} / \mathrm{mm}^{3}\right)$, viral load $(\log$ transformed to account for skewed distribution), drug susceptibility, i.e. MDR-TB (yes/no), defined according to Peruvian guidelines for HIV and TB treatment (MINSA 2013) were also included. These data were obtained from clinical records.

\section{Procedures}

After assessing selection criteria, suitable patients were invited to participate. All the patients gave their consent. Patients were requested to answer a detailed questionnaire regarding their sociodemographic backgrounds as well as their HIV and TB history. After completing the questionnaires, and before taking body composition measure, patients were asked to empty their bladder and bare their feet to guarantee adequate results. They were then asked to stand on the metal pads of the BIA device with the arms hanging on each side as per manufacturer's instructions (TANITA 2012). Their weight, BMI, fat mass, lean mass and total body water composition were automatically calculated by the device. Data regarding $\mathrm{CD}_{4}$ level and viral load were obtained from their clinical records, as routine management of HIV-infected patients requires these results before starting treatment. In addition, M. tuberculosis drug susceptibility was also evaluated as part of the National Tuberculosis Control and Prevention Strategy (MINSA 2013).

Follow-up assessments were performed at the end of every month of therapy, as per the National Tuberculosis Control and Prevention Strategy's schedule. Under the Directly Observed Treatment, Short-Course Strategy (DOTS), patients are weighed routinely using a traditional scale. Instead of this technique, patients were evaluated using the body composition analyzer. At the completion of the study, each patient's TB treatment outcome data were collected from clinical records; mortality was confirmed by using the death notification form of the ESN-PCT.

\section{Ethical issues}

This study was approved by the Institutional Ethical Committee of the Universidad Peruana Cayetano Heredia, Lima, Peru, number 16-2014. In addition, each of the ethical committees of the hospitals also approved the study before beginning the activities. This study obtained the patients' consent before research activities and their confidentiality was also guaranteed.

\section{Statistical analysis}

Microsoft Excel for Windows was utilized for double data entry process. STATA version 13.0 for Windows (STATA Corp, College Station, TX, US) was used for analysis. 
Initially, a description of demographic and clinical characteristics was tabulated according to mortality. Categorical variables were compared using Chi squared or Fisher's exact test as appropriate, whereas numerical variables were compared using the Student's t test. In addition, mean and standard deviation (SD) of BIA anthropometric markers, in $\mathrm{Kg}$, were calculated for each outcome group according to the month of follow-up. Finally, a random effects model was fitted to estimate average weight trends for patients who died and those who survived (Hardin et al., 2003). An a priori model - used in other publications (Bernabe et al., 2011; Chung et al., 2014)- was used to estimate the variation of the proposed anthropometric markers over time:

$$
Y_{i j}=\beta_{0}+\beta_{1} . \text { Outcome }+\beta_{2} \cdot T_{i j}+\beta_{3} . T_{i j} . \text { Outcome }
$$

Where $\mathrm{Y}_{\mathrm{ij}}$ is the mean of any of the proposed anthropometrical markers (i.e. weight, fat mass, lean masn, total body water, or BMI) in $\mathrm{kg}$ in patient "i" at time " $\mathrm{j}$ "; $\beta_{0}$ is the intercept, for example, fat mass in kilograms among those who survived at baseline; $\beta_{1}$ is the difference in the selected anthropometrical marker in patiens who died compared to those who survived; $\beta_{2}$ quantifies the change of selected marker between baseline and one selected month for participants who survived; and the sum of $\beta_{2}$ and $\beta_{3}$ (interaction term) represents the variation in the selected marker between baseline and one month for participants who died (Fitzmaurice et al., 2004; Hanley et al., 2003). Robust standard errors were used to handle misspecification of variance correlation functions. Potential confounders included in the model were age, sex, drug susceptibility, and $\mathrm{CD}_{4}$ count. We decided for this group of variables as many of them were highly correlated, especially those related to HIV prognosis (i.e. $\mathrm{CD}_{4}$ count, viral load, HAART, and co-morbidities).

\section{Results}

Population characteristics at baseline

A total of 134 pulmonary tuberculosis and HIV-infected patients who started TB treatment during the study period were contacted; however, 9 were excluded from further analyses ( 4 abandoned therapy, 3 changed treatment regimen, and 2 were transferred to another facility). Therefore, 125 patients were analyzed. $86(68.8 \%)$ were male patients and mean age was 36.9 (SD: 13.5, range 15 - 88) years. The characteristics of the population according to treatment outcome status are shown in Table 1. There was no significant difference in age or sex between the two groups. All of the patients who died during treatment had a CD4 count $<200$ cells $/ \mathrm{mm} 3$, whereas those who survived, one third, had a CD4 count greater than or equal to 200 cells $/ \mathrm{mm} 3$. Viral load was higher in patients who died during treatment.

Table 1: Characteristics of the study population at baseline according to tuberculosis treatment outcome

\begin{tabular}{lccc}
\hline & $\begin{array}{c}\text { Survived to } \\
\text { months } \\
(\mathbf{n = 1 0 8})\end{array}$ & $\begin{array}{c}\text { Died during TB } \\
\text { treatment } \\
(\mathbf{n}=\mathbf{1 7})\end{array}$ & p-value* \\
\hline Sex & $32(82.1 \%)$ & $7(17.9 \%)$ & 0.40 \\
Female & $76(88.4 \%)$ & $10(11.6 \%)$ & \\
Male & & & \\
Age & $35.7(15.2)$ & $42.2(15.6)$ & 0.10 \\
Mean (SD) & & & \\
CD4 count & $72(66.7 \%)$ & $15(100 \%)$ & 0.005 \\
$<200$ cells/mm ${ }^{3}$ & $36(33.3 \%)$ & $0(0.0 \%)$ & \\
$\geq 200$ cells/mm ${ }^{3}$ & & & 0.01 \\
Viral load (Log) & $10.8(3.6)$ & $13.2(1.3)$ & \\
Mean (DE) & & & 0.39 \\
Drug susceptibility & $95(88.0 \%)$ & $13(76.5 \%)$ & \\
No MDR & $11(10.2 \%)$ & $3(1.8 \%)$ & \\
MDR-TB & & & \\
HAART during TB treatment & $82(75.9 \%)$ & $8(7.4 \%)$ & $<0.001$ \\
No & $4(3.7 \%)$ & $9(8.3 \%)$ & \\
Yes & & & \\
Previous prophylaxis with isoniazid & & & \\
\hline
\end{tabular}


Presence of co-morbidity

No

$99(91.7 \%)$

$10(9.3 \%)$

0.001

Yes

$\mathrm{SD}=$ standard deviation $=$ multidrug-resistant $\mathrm{TB}$

* Fisher's exact test was used to calculate the p-value in the case of categorical variables, and Student t test for numerical variables. ${ }^{\&}$ Isoniazid

\section{Death and variation over time of BIA anthropometric markers}

Seventeen (13.6\%) participants died during TB treatment: 5 deaths occurred in the first month, 4 in the second month, and 8 after the second month. A detailed description of the variation in selected anthropometric markers is shown in Table 2. Almost all of the BIA markers decreased among those who died, with special emphasis on fat mass. Nonetheless, lean mass (free-fat mass) was almost constant among those who survived and those who died.

Table 2: Change in anthropometric markers related to body composition during the first two months of treatment

\begin{tabular}{|c|c|c|c|c|c|c|}
\hline & \multicolumn{2}{|c|}{ Baseline } & \multicolumn{2}{|c|}{ First month } & \multicolumn{2}{|c|}{ Second month } \\
\hline & $\mathbf{n}$ & Mean (SD) & $\mathbf{n}$ & Mean (SD) & $\mathbf{n}$ & Mean (SD) \\
\hline \multicolumn{7}{|l|}{ Weight (Kg) } \\
\hline $\begin{array}{l}\text { Survived to therapy } \\
\text { completion }\end{array}$ & 108 & $55.3(10.4)$ & 108 & $56.5(10.7)$ & 108 & $57.8(10.8)$ \\
\hline $\begin{array}{l}\text { Died prior to therapy } \\
\text { completion }\end{array}$ & 17 & $56.7(10.5)$ & 12 & $56.2(10.3)$ & 8 & $54.4(10.6)$ \\
\hline \multicolumn{7}{|l|}{ Total body water (Kg) } \\
\hline Cured & 108 & $33.2(6.2)$ & 108 & $33.9(6.4)$ & 108 & $34.7(6.5)$ \\
\hline Died & 17 & $34.0(6.3)$ & 12 & $33.7(6.2)$ & 8 & $32.6(6.4)$ \\
\hline \multicolumn{7}{|l|}{ Fat mass (Kg) } \\
\hline Cured & 108 & $9.6(5.2)$ & 108 & $10.8(5.5)$ & 108 & $11.9(6.0)$ \\
\hline Died & 17 & $10.5(5.0)$ & 12 & $8.2(2.4)$ & 8 & $7.9(2.6)$ \\
\hline \multicolumn{7}{|l|}{ Lean mass (Kg) } \\
\hline Cured & 108 & $45.6(9.9)$ & 108 & 45.7 (9.9) & 108 & $45.9(9.8)$ \\
\hline Died & 17 & $46.1(9.3)$ & 12 & $47.9(9.5)$ & 8 & $46.5(9.1)$ \\
\hline \multicolumn{7}{|l|}{ BMI $\left(\mathbf{K g} / \mathbf{m}^{2}\right)$} \\
\hline Cured & 108 & $20.9(3.1)$ & 108 & $21.4(3.3)$ & 108 & $21.9(3.4)$ \\
\hline Died & 17 & $22.1(4.5)$ & 12 & $20.6(3.7)$ & 8 & $20.5(4.3)$ \\
\hline
\end{tabular}

$\mathrm{SD}=$ Standard Deviation; BMI = Body Mass Index

\section{Variation of anthropometric markers over time and treatment outcome}

Results of crude and adjusted mixed linear models are shown in Table 3. There was no difference in baseline anthropometric markers between patients who died and survived; however, the interaction terms in all five markers were statistically significant $(\mathrm{p}<0.001)$. As a consequence, results suggest that HIV-infected patients who died during TB treatment lost $1.8 \mathrm{~kg}$ of weight $(\mathrm{p}<0.001), 0.9 \mathrm{~kg}$ of fat mass $(\mathrm{p}<0.001)$, and $0.8 \mathrm{~kg}$ of lean mass $(\mathrm{p}=0.008)$ at the end of the first month of therapy; whereas at the end of the second month, those patients lost $2.8 \mathrm{~kg}$ of weight $(p<0.001), 1.5 \mathrm{~kg}$ of fat mass $(\mathrm{p}<0.001)$ and $1.3 \mathrm{~kg}$ of lean mass $(\mathrm{p}=0.03)$. In contrast, patients who survived, gained $1.3 \mathrm{~kg}$ of weight $(\mathrm{p}<0.001)$ and $1.2 \mathrm{~kg}$ of fat mass $(\mathrm{p}<0.001)$, but not lean mass $(\mathrm{p}=0.59)$ at the end of first month of treatment; whereas gained $2.6 \mathrm{~kg}$ of weight $(\mathrm{p}<0.001)$ and $2.3 \mathrm{~kg}$ of fat mass $(\mathrm{p}<0.001)$, but not lean mass $(\mathrm{p}=0.20)$ at the end of the second month of therapy (Figure 1). Similar results were obtained when body water and body mass index were evaluated. 
Table 3: Change in anthropometric markers related to body composition during the first two months of TB treatment: crude and adjusted random effects models

\begin{tabular}{|c|c|c|c|c|c|c|}
\hline & \multicolumn{2}{|c|}{ Weight (Kg) } & \multicolumn{2}{|c|}{ Fat mass $(\mathrm{Kg})$} & \multicolumn{2}{|c|}{ Lean mass (Kg) } \\
\hline & $\beta(95 \% \mathrm{CI})$ & p-value & $\beta(95 \%$ CI ) & p-value & $\beta(95 \% \mathrm{CI})$ & p-value \\
\hline \multicolumn{7}{|l|}{ Crude model } \\
\hline Intercept & $55.3(53.3 ; 57.2)$ & $<0.001$ & $9.6(8.7 ; 10.6)$ & $<0.001$ & $45.6(43.8 ; 47.5)$ & $<0.001$ \\
\hline Dead & $1.39(-3.9 ; 6.7)$ & 0.61 & $0.90(-1.62 ; 1.43)$ & 0.49 & $0.49(-4.25 ; 5.23)$ & 0.84 \\
\hline Time ( $1^{\text {st }}$ month $)$ & $1.25(1.00 ; 1.50)$ & $<0.001$ & $1.18(0.92 ; 1.43)$ & $<0.001$ & $0.08(-0.24 ; 0.40)$ & 0.64 \\
\hline Time ( $2^{\text {nd }}$ month $)$ & $2.55(2.11 ; 2.99)$ & $<0.001$ & $2.24(1.86 ; 2.62)$ & $<0.001$ & $0.31(-0.15 ; 0.78)$ & 0.18 \\
\hline Died $*$ Time $\left(1^{\mathrm{st}}\right.$ month $)$ & $-3.03(-3.83 ;-2.24)$ & $<0.001$ & $-2.17(-2.57 ;-1.77)$ & $<0.001$ & $-0.88(-1.55 ;-0.21)$ & 0.01 \\
\hline Died $*$ Time $\left(2^{\text {nd }}\right.$ month $)$ & $-5.33(-6.55 ;-4.12)$ & $<0.001$ & $-3.76(-4.31 ;-3.22)$ & $<0.001$ & $-1.59(-2.99 ;-0.18)$ & 0.03 \\
\hline \multicolumn{7}{|l|}{ Adjusted model* } \\
\hline Intercept & $48.7(43.2 ; 54.3)$ & $<0.001$ & $7.8(4.8 ; 10.8)$ & $<0.001$ & $40.9(36.0 ; 45.8)$ & $<0.001$ \\
\hline Dead & $1.94(-4.36 ; 8.24)$ & 0.55 & $-0.68(-3.11 ; 1.75)$ & 0.58 & $2.62(-2.88 ; 8.11)$ & 0.35 \\
\hline Time ( $1^{\text {st }}$ month $)$ & $1.27(1.01 ; 1.52)$ & $<0.001$ & $1.18(0.92 ; 1.44)$ & $<0.001$ & $0.09(-0.24 ; 0.42)$ & 0.59 \\
\hline Time ( $2^{\text {nd }}$ month $)$ & $2.57(2.12 ; 3.01)$ & $<0.001$ & $2.26(1.87 ; 2.65)$ & $<0.001$ & $0.31(-0.16 ; 0.78)$ & 0.20 \\
\hline Died $*$ Time $\left(1^{\text {st }}\right.$ month $)$ & $-3.06(-3.87 ;-2.25)$ & $<0.001$ & $-2.12(-2.54 ;-1.73)$ & $<0.001$ & $-0.92(-1.61 ;-0.24)$ & 0.008 \\
\hline Died $*$ Time $\left(2^{\text {nd }}\right.$ month $)$ & $-5.34(-6.55 ;-4.13)$ & $<0.001$ & $-3.73(-4.30 ;-3.20)$ & $<0.001$ & $-1.59(-2.98 ;-0.19)$ & 0.03 \\
\hline
\end{tabular}

$95 \% \mathrm{CI}=95 \%$ confidence interval

* Adjusted for age, sex, drug susceptibility and $\mathrm{CD}_{4}$ count. 
2a. Weight variation over time*

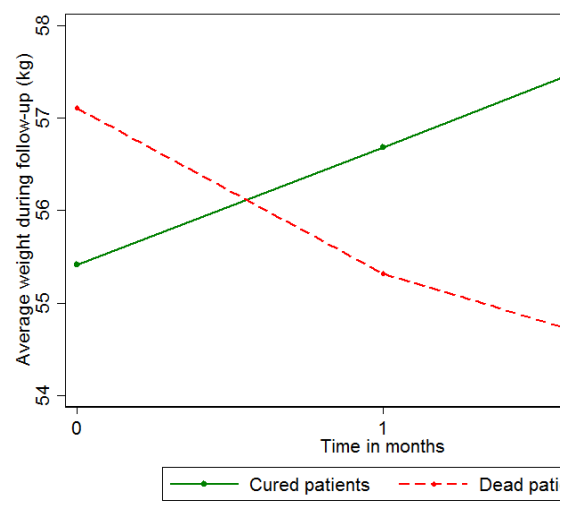

2b. Fat mass variation over time*

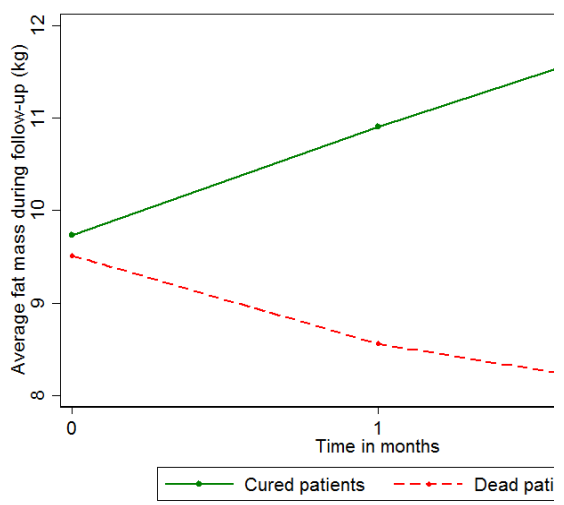

2c. Lean mass variation over time*

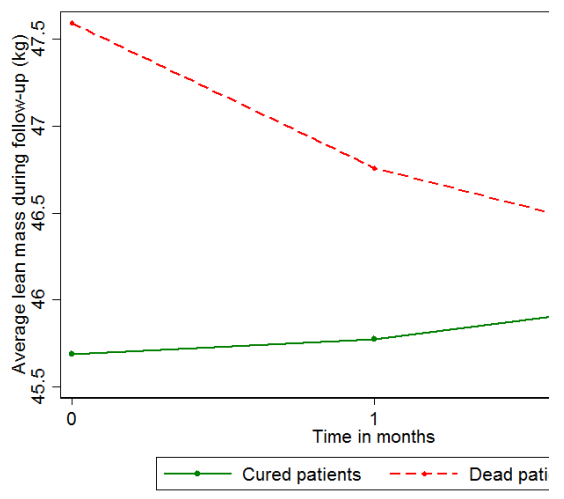

Figure 1: Variation over time of selected anthropometric markers: weight (2a), fat mass (2b) and lean mass (2c) during TB treatment among HIV-infected patients. * Predicted lines were calculated using random effect models adjusting by age, sex, drug susceptibility and $\mathrm{CD}_{4}$ count.

\section{Discussion \\ Main findings}

This study demonstrated the variation of different anthropometrical markers (i.e. body weight, but also fat mass and other BIA markers) during the first two months of tuberculosis treatment among HIV-coinfected patients. Accordingly, these markers can potentially predict death among these patients after controlling for potential confounders such as age, sex, drug susceptibility and $\mathrm{CD}_{4}$ count: patients with good outcome at the end of therapy gained weight, BMI, fat mass and total body water, but not lean mass (non-fat mass). In contrast, patients who died during TB treatment lost weight, fat mass, lean mass, body water and BMI.

\section{Comparison with previous studies}

Previous studies have reported a significant increase in weight in patients with good outcome at the end of TB treatment, and a decrease among patients with poor outcome (i.e. those who died) (Bernabe-Ortiz et al., 2011; Hoa et al., 2013; Khan et al., 2006; Krapp et al., 2008; Vasantha et al., 2014). Approximately $1 \mathrm{~kg}$ is lost in the first month of therapy among patients with TB who died during treatment, even in patients with MDR-TB (Chung-Delgado et al., 2014). However, these results have been obtained mainly from non HIV-infected individuals. Our findings, assessing HIV-infected patients diagnosed with TB follow the same trend: a weight loss of $1.8 \mathrm{~kg}$ in the first month of therapy, and more than $2.5 \mathrm{~kg}$ at the end of the second month. Therefore, it seems that weight loss can be also a good predictor of TB treatment outcome among HIV-infected individuals (Kennedy et al., 1996; Schwenk et al., 2004).

Our results also expand on previous studies by reporting a reduction in other anthropometric markers (fat mass, lean mass, total body water, and BMI) among HIV-infected patients who died during TB treatment. Apparently, weight loss was mainly due to fat mass reduction $(52.5 \%$ in the first month and $53.1 \%$ in the second month) instead of lean mass $(47.5 \%$ in the first month and $46.9 \%$ in the second month). However, a previous report implies that lean mass reduction can be a better predictor of mortality than weight loss (Suttmann et al., 1995). Wasting occurs frequently during HIV infection and increases with disease progression. As malnutrition is common among HIV-infected individuals, especially where there is coinfection with TB, bioimpedance analysis might be a good approach to prevent deaths among patients with the TB-HIV coinfection (Diouf et al., 2009).

Decline in total body water during TB treatment deserves attention. Overall, body water content remains stable during adulthood; however, changes in total water have been associated with HIV infection (Diouf et al., 2009). Dehydration might be one of the most common consequences derived from a severe disease, but also from malnutrition or inadequate treatment. Consequently, participants with a reduction in water should be accurately assessed to determine the potential cause of this, such as drug-resistant forms of TB, poor HIV infection management, or concomitant coinfections. On the other hand, BMI reduction was also verifiable in coinfected patients who died; however, these results were expected as BMI decline derives from weight decrease.

\section{Public health relevance}

Our findings corroborate that weight can be a good predictor of TB treatment outcome among HIV-infected individuals. Weight measurement, an easy and non-invasive procedure, has been little considered in the past, but currently it has been included in many management guidelines (Hoa et al., 2013; MINSA 2013). Some studies have demonstrated that HIV-infected patients with TB have a higher prevalence of wasting compared with patients with TB alone (Scalcini et al., 1991). Hhowever, weight 
variation found in our study was similar to that seen in patients without HIV. A larger study assessed weight loss in HIV-infected patients and two different patterns were observed: episodes of acute severe weight loss and episodes of chronic unremitting progressive weight loss (Macallan et al., 1993). As a result, our results suggest that a close monitoring of weight and other anthropometric markers among HIV-infected patients in tuberculosis treatment is needed, and further studies are required to better understand strategies to reduce mortality among these individuals.

\section{Strengths and limitations}

Strenghts of this study include the prospective nature of the data collection as well as the use of five different anthropometric markers to predict death among HIV-infected patients during TB treatment. However, this study also has some limitations. First, data obtained during the first two months of TB therapy only were used in the analysis instead of the total treatment duration. A closer monitoring of weight and the other BIA markers (i.e weekly or twice a month) is needed to better characterize their variation over time. However, this approach can be justified because the focus of the manuscript was the value of these measurements to predict TB treatment outcome, and this prediction is likely to take place at months one and two, when patients are routinely assessed according to National Tuberculosis Control Programme guidelines. Secondly, deaths that occurred during follow-up might not have been attributable to TB. Nevertheless, 9 out of 17 deaths were in the first two months of treatment and it has been suggested that most deaths due to TB occured during the first months of treatment (Mathew et al., 2006). Thirdly, variation of anthropometric markers might be due to other comorbidities, not explored in this study. However, changes in body composition seen in patients with HIV and TB are very different from those observed in patients with HIV who may suffer from lipodystrophy which is characterized by the predominant fat atrophy in the arms and legs, and abdomen fat increase (Carr et al., 2003). Finally, whilst we showed a strong correlation, our findings must be verified in a larger prospective study in which changes in body mass composition are used to predict treatment outcome.

\section{Conclusions}

Our results evidenced that different anthropometric markers might help to predict the progress towards death among patients with HIV and TB coinfection. A comprehensive assessment of patients with HIV and TB coinfection must be performed to prevent deaths during treatment. Weight change must be evaluated routinely during clinical assessment in order to detect failure to respond the treatment and to implement appropriate management strategies for the patient.

Conflict of interest: The authors declare that they have no competing interests.

Authors' contributions: RM, RHG, DK and ABO conceived, designed and supervised the overall study. ABO and RM led the statistical analysis. RM, RHG, DK and ABO participated in writing the manuscript providing important intellectual content and gave their final approval of this version to be published.

Acknowledgments: The authors are indebted to all participants who kindly agreed to participate in the study. Special thanks to all field teams for their commitment and hard work. We would like to thank Lucero Curiñaupa Vilchez and FIMRC (Fundation for International Relief for Children) for the review of this article.

\section{References}

1. Ackah AN, Coulibaly D, Digbeu H, Diallo K, Vetter KM, Coulibaly IM, Greenberg AE, De Cock KM. (1995). Response to treatment, mortality and CD4 lymphocyte counts in HIV-infected persons with tuberculosis in Abidjan, Cote d'Ivoire. Lancet; 345(8950):607-10.

2. Bernabe-Ortiz A, Carcamo CP, Sanchez JF, Rios J. (2011). Weight variation over time and its association with tuberculosis treatment outcome: a longitudinal analysis. PLoS One; 6(4):e18474.

3. Carr A, Emery S, Law M, Puls R, Lundgren JD, Powderly WG. (2003). An objective case definition of lipodystrophy in HIV-infected adults: a case-control study. Lancet ;361(9359):726-35.

4. Chung-Delgado K, Revilla-Montag A, Guillen-Bravo S, Bernabe-Ortiz A. (2014). Weight variation over time and its relevance among multidrug-resistant tuberculosis patients. The International Journal Infectious Diseases;23:20-4.

5. Crampin AC, Mwaungulu JN, Mwaungulu FD, Mwafulirwa DT, Munthali K, Floyd S, et al. (2010). Recurrent TB: relapse or reinfection? The effect of HIV in a general population cohort in Malawi. AIDS;24(3):417-26.

6. Diouf A, Gartner A, Dossou NI, Sanon DA, Bluck L, Wright A, Wade S. ( 2009). Validity of impedance-based predictions of total body water as measured by $2 \mathrm{H}$ dilution in African HIV/AIDS outpatients. British Journal Nutrition;101(9):1369-77.

7. Dioum A, Gartner A, Cisse AS, Delpeuch F, Maire B, Wade S, Schutz Y. (2005). Validity of impedance-based equations for the prediction of total body water as measured by deuterium dilution in African women. The American Journal Clinical Nutrition;81(3):597-604.

8. Fitzmaurice GM, Laird NM, Ware JH. (2004). Applied longitudinal analysis. Wiley-Interscience, editor. New Jersey, US: John Wiley \& Sons, Inc. 
9. Hanley JA, Negassa A, Edwardes MD, Forrester JE. (2003). Statistical analysis of correlated data using generalized estimating equations: an orientation. American Journal of Epidemiology;157(4):364-75.

10. Hardin J, Hilbe JM. (2003). Generalized Estimating Equations. Hall/CRC C, editor. Washington DC, US: CRC Press Company.

11. HIV/AIDS JUNPo. (2013). Global report: UNAIDS report on the global AIDS epidemic 2013. Geneva, Switzerland: UNAIDS.

12. Hoa NB, Lauritsen JM, Rieder HL. (2013). Changes in body weight and tuberculosis treatment outcome in Vietnam. International Journal of Tuberculosis and Lung Diseases;17(1):61-6.

13. Khan A, Sterling TR, Reves R, Vernon A, Horsburgh CR. (2006). Lack of weight gain and relapse risk in a large tuberculosis treatment trial. American Journal of Respiratory and Critical Care Medicine;174(3):344-8.

14. Kennedy N, Ramsay A, Uiso L, Gutmann J, Ngowi FI, Gillespie SH. (1996). Nutritional status and weight gain in patients with pulmonary tuberculosis in Tanzania. Transactions of the Royal Society of Tropical Medicine and Hygiene;90(2):1626.

15. Krapp F, Veliz JC, Cornejo E, Gotuzzo E, Seas C. (2008). Body weight gain to predict treatment outcome in patients with pulmonary tuberculosis in Peru. International Journal of Tuberculosis and Lung Disease;12(10):1153-9.

16. Macallan DC, Noble C, Baldwin C, Foskett M, McManus T, Griffin GE. (1993). Prospective analysis of patterns of weight change in stage IV human immunodeficiency virus infection. The American Journal of Clinical Nutrition;58(3):417-24.

17. Mathew TA, Ovsyanikova TN, Shin SS, Gelmanova I, Balbuena DA, Atwood S, Peremitin GG, Streles AK, Murray MB. (2006). Causes of death during tuberculosis treatment in Tomsk Oblast, Russia. International Journal of Tuberculosis and Lung Disease; $10(8): 857-63$.

18. Ministerio de Salud (2013). Estrategia Sanitaria Nacional de Prevencion y Control de la Tuberculosis: Norma tecnica para el control de la tuberculosis. Lima, Peru: MINSA.

19. Mupere E, Zalwango S, Chiunda A, Okwera A, Mugerwa R, Whalen C. (2010). Body composition among HIVseropositive and HIV-seronegative adult patients with pulmonary tuberculosis in Uganda. Annals of Epidemiology; 20(3):210-6.

20. Ott M, Lembcke B, Fischer H, Jager R, Polat H, Geier H, Rech M, Staszeswki S, Helm EB, Caspary WF. (1993). Early changes of body composition in human immunodeficiency virus-infected patients: tetrapolar body impedance analysis indicates significant malnutrition. The American Journal of Clinical Nutrition;57(1):15-9.

21. Pawlowski A, Jansson M, Skold M, Rottenberg ME, Kallenius G. (2012). Tuberculosis and HIV co-infection. PLoS Pathogens;8(2):e1002464.

22. Scalcini M, Occenac R, Manfreda J, Long R. (1991). Pulmonary tuberculosis, human immunodeficiency virus type-1 and malnutrition. Bulletin of the International Union against Tuberculosis and Lung Diseases;66(1):37-41.

23. Schon T, Idh J, Westman A, Elias D, Abate E, Diro E, Moges F, Kassu A, Ayele B, Forslund T. (2011). Effects of a food supplement rich in arginine in patients with smear positive pulmonary tuberculosis--a randomised trial. Tuberculosis (Edinb);91(5):370-7.

24. Schwenk A, Macallan DC. (2000). Tuberculosis, malnutrition and wasting. Current Opinion in Clinical Nutrition \& Metabolic Care;3(4):285-91.

25. Schwenk A, Beisenherz A, Kremer G, Diehl V, Salzberger B, Fatkenheuer G. (1999). Bioelectrical impedance analysis in HIV-infected patients treated with triple antiretroviral treatment. The American Journal of Clinical Nutrition;70(5):86773.

26. Schwenk A, Hodgson L, Wright A, Ward LC, Rayner CF, Grubnic S, Griffin GE, Macallan DC. (2004). Nutrient partitioning during treatment of tuberculosis: gain in body fat mass but not in protein mass. The American Journal of Clinical Nutrition;79(6):1006-12.

27. Sonnenberg P, Murray J, Glynn JR, Shearer S, Kambashi B, Godfrey-Faussett P. (2001). HIV-1 and recurrence, relapse, and reinfection of tuberculosis after cure: a cohort study in South African mineworkers. Lancet;358(9294):1687-93.

28. Suttmann U, Ockenga J, Selberg O, Hoogestraat L, Deicher H, Muller MJ. (1995). Incidence and prognostic value of malnutrition and wasting in human immunodeficiency virus-infected outpatients. Journal of Acquired Immune Deficiency Syndromes;8(3):239-46.

29. TANITA Corporation. (2012). Body composition analyzer goal setter: TBF-300A Instruction manual. Tokyo, Japan: TANITA.

30. Vasantha M, Venkatesan P. (2014). Structural equation modeling of latent growth curves of weight gain among treated tuberculosis patients. PLoS One;9(3):e91152.

31. Zhang M, Kim KJ, Iyer D, Lin Y, Belisle J, McEnery K, Crandall FD, Barnes PF. (1997). Effects of Mycobacterium tuberculosis on the bioelectric properties of the alveolar epithelium. Infection and Immunity;65(2):692-8.

32. Zhou L, He X, He D, Wang K, Qin D. (2011). Biosensing technologies for Mycobacterium tuberculosis detection: status and new developments. Clinical \& Developmental Immunology;2011:193963. 